\title{
Centrosomal protein centrin is not detectable during early pre-implantation development but reappears during late blastocyst stage in porcine embryos
}

\author{
G Manandhar ${ }^{1}$, D Feng ${ }^{1}$, Y-J Yi ${ }^{1}$, L Lai ${ }^{1}$, J Letko $^{2}$, J Laurincik $^{3}$, M Sutovsky $^{1}$, J L Salisbury ${ }^{4}$, \\ R S Prather ${ }^{1}$, H Schatten $^{5}$ and P Sutovsky ${ }^{1,6}$ \\ ${ }^{1}$ Department of Animal Sciences, University of Missouri, S-141 ASRC, 920 E Campus Drive, Columbia, Missouri

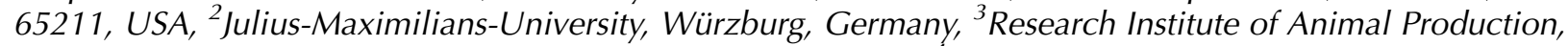 \\ Constantine the Philosopher University, Nitra, Slovak Republic, ${ }^{4}$ Tumor Biology Program, Mayo Clinic, Rochester, \\ Minnesota, USA, ${ }^{5}$ Department of Veterinary Pathobiology, University of Missouri, Columbia, Missouri, USA and \\ ${ }^{6}$ Obstetrics and Gynecology, University of Missouri, Columbia, Missouri, USA
}

Correspondence should be addressed to G Manandhar; Email: manandharg@missouri.edu

\begin{abstract}
Centrin is an evolutionarily conserved $20 \mathrm{kDa}, \mathrm{Ca}^{+2}$-binding, calmodulin-related protein associated with centrioles and basal bodies of phylogenetically diverse eukaryotic cells. Earlier studies have shown that residual centrosomes of non-rodent mammalian spermatozoa retain centrin and, in theory, could contribute this protein for the reconstruction of the zygotic centrosome after fertilization. The present work shows that CEN2 and CEN3 mRNA were detected in germinal vesicle-stage (GV) oocytes, MII oocytes, and pre-implantation embryos from the two-cell through the blastocyst stage, but not in spermatozoa. Boar ejaculated spermatozoa possess centrin as revealed by immunofluorescence microscopy and western blotting. Immature, GV oocytes possess speckles of centrin particles in the perinuclear area, visualized by immunofluorescence microscopy and exhibit a $19 \mathrm{kDa}$ band revealed by western blotting. Mature MII stage oocytes lacked centrin that could be detected by immunofluorescence or western blotting. The sperm centrin was lost in zygotes after in vitro fertilization. It was not detectable in embryos by immunofluorescence microscopy until the late blastocyst stage. Embryonic centrin first appeared as fine speckles in the perinuclear area of some interphase blastocyst cells and as putative centrosomes of the spindle poles of dividing cells. The cells of the hatched blastocysts developed centrin spots comparable with those of the cultured cells. Some blastomeres displayed undefined curved plate-like centrin-labeled structures. Anti-centrin antibody labeled interphase centrosomes of cultured pig embryonic fibroblast cells as distinct spots in the juxtanuclear area. Enucleated pig oocytes reconstructed by electrofusion with pig fibroblasts displayed centrin of the donor cell during the early stages of nuclear decondensation but became undetectable in the late pronuclear or cleavage stages. These observations suggest that porcine zygotes and pre-blastocyst embryonic cells lack centrin and do not retain exogenously incorporated centrin. The early embryonic centrosomes function without centrin. Centrin in the blastocyst stage embryos is likely a result of de novo synthesis at the onset of differentiation of the pluripotent blastomeres.

Reproduction (2006) 132 423-434
\end{abstract}

\section{Introduction}

The centrosome has remained a mysterious cell organelle despite an enormous amount of research devoted to it during the past century. Centrosome studies were started in gametes at the beginning of the last century (Boveri 1900, Wilson 1924), revived in gametic cells in the middle of the century (Mazia et al. 1960), and now being advanced in the ooplasmic cell-free system (Palazzo et al. 1992, Heald et al. 1997, Hinchcliffe et al.
1999). The centrosome undergoes remarkable changes during gametogenesis and fertilization, unparalleled in other cellular systems. Centrosomes of male gametes lose most of the centrosomal proteins, degenerate centrioles partially or completely, and remain quiescent until fertilization (Manandhar et al. 2000). The female gametes on the other hand degenerate centrioles completely, disperse the centrosomal proteins in the cytoplasm, and switch to an acentrosomal mode of spindle organization (Manandhar et al. 2005). Hence, 
spermatogenesis and oogenesis are the most suitable systems for investigating the molecular pathway of centrosomal attenuation. Due to centrosome reduction, the oocytes switch to an acentrosomal mode and therefore provide an ideal system for studying the molecular mechanisms of spindle organization, and the role of the centrosome in this process in vivo without invasive knockout or knockdown manipulations. Such studies have been fairly well advanced in insect systems (Riparbelli et al. 2005). After fertilization, the residual sperm centrioles assemble embryonic centrosomes by recruiting the centrosomal proteins from the oocyte cytoplasm (Schatten 1994). Because the sperm centrioles are partially or completely degenerated, a question was raised whether the zygotic or early embryonic centrosomes are equivalent to those of the cycling somatic cells (Manandhar et al. 2005).

Among various resident molecules of centrosomes, centrins are $20 \mathrm{kDa}, \mathrm{Ca}^{+2}$-binding contractile proteins occurring in undifferentiated cells of phylogenetically diverse eukaryotic organisms (Salisbury 1995, Schiebel \& Bornens 1995) and in differentiated cells in which centrioles are conserved (Wolfrum 1991, 1992, 1995). The pericentriolar proteins (e.g., $\gamma$-tubulin) do not always accompany canonical centrosomes, as they can exist outside the centrosome in some cells (Novakova et al. 1996, Wilson et al. 1997) or be present in the spindle poles/astral foci lacking an organized centrosome (Gueth-Hallonet et al. 1993, Palacios et al. 1993, Callaini et al. 1999). In contrast, centrin is intimately associated with the microtubular triplets (Wolfrum 1995, Manandhar et al. 1999) or the distal lumen of centrioles (Levy et al. 1996, Paoletti et al. 1996). During mouse and primate spermiogenesis, centriole degeneration is correlated with the loss of their centrin labeling (Manandhar et al. 1999, Manandhar \& Schatten 2000). Taken together, these studies suggest that punctate centrin localization can be used as a marker of centrioles.

Mammals have several isoforms of centrin (Paoletti et al. 1996). Three have been well defined and expressed in different types of cells, specializing in different functions. Centrin-2 (cen2p) is ubiquitously expressed in somatic cells (Wolfrum \& Salisbury 1998, Hart et al. 1999) and involved in centriole replication (Salisbury et al. 2002). Human CEN2 is localized in the chromosome Xq28 (Tanaka et al. 1994, Chatterjee et al. 1995). Human Centrin-1 gene (HsCEN1) is intron-less retroposon derived from CEN2 and localized in the chromosome 18A2 (Errabolu et al. 1994, Hart et al. 1999). It is expressed in developing spermatids when the expression of CEN2 is shut down (Hart et al. 1999). Besides spermatids, CEN1 expression has been found in differentiating ciliated cells of the retina (Wolfrum \& Salisbury 1998) and nasal epithelium (Laoukili et al. 2000). Hence, it is likely to be involved in the formation of axonemes of the motile organelles. The Centrin-3 gene (CEN3) is more closely related to yeast CDC31 than to CEN1 or CEN2. Yeast cdc31p is localized in the bridge of the spindle pole body (SPB) playing an important role in the SPB duplication (Baum et al. 1986). Human cen3p is expressed less abundantly in somatic epithelial cells (LeDizet et al. 1998, Laoukili et al. 2000) and mainly enriched in centrosomes. Therefore, it may be important for ciliogenesis or centriole replication. Cen3p migrates slower in SDS-PAGE $(\sim 23 \mathrm{kDa})$ than cen $1 \mathrm{p} / 2 \mathrm{p}$ (Middendorp et al. 1997).

Centrin follows unique mode of degeneration during spermatogenesis in different animal species. Mouse spermatozoa lose centrin completely along with the centioles (Manandhar et al. 1999). In primates, it is partially degenerated correlating with the partial degradation of distal centrioles (Manandhar \& Schatten 2000). Hence, the spermatozoa are likely to contribute centrin to the embryonic centrosomes in higher mammals. The present work has shown that boar spermatozoa possess centrin similar to primate spermatozoa. But the oocytes do not retain the gametic centrin contributed by spermatozoa after in vitro fertilization (IVF) or the somatic centrin contributed by pig embryonic fibroblast (PEF) after somatic cell nuclear transfer (SCNT). Despite the presence of residual CEN1, CEN2 mRNAs in the oocytes and embryos, the embryonic centrin is regenerated only during late blastocyst stage.

\section{Materials and Methods}

\section{Antibodies}

Anti-centrin antibody mAb $20 \mathrm{H} 5$ was produced against the conserved $\mathrm{C}$ terminus of Chlamydomonas centrin. The antibody has been used in several earlier investigations to study centrin of somatic cells (Paoletti et al. 1996) and residual centrin of spermatogenic cells (Manandhar et al. 1999, Manandhar \& Schatten 2000). The specificity of $\mathrm{mAb} 2 \mathrm{OH} 5$ to recognize centrins has been shown by western blotting experiments with purified, recombinant human cen $1 p$ and cen2p (Middendorp et al. 1997). In the present study, $\mathrm{mAb} 20 \mathrm{H} 5$ was used at $500 \times$ dilution for immunofluorescence and $5000 \times$ dilution for western blotting. Anti- $\beta$-tubulin antibody E7 was purchased from Developmental Studies Hybridoma Bank, University of lowa, IA, USA. It was used at $40 \times$ dilution for immunofluorescence and $2000 \times$ dilution for western blotting experiments. Secondary antibodies conjugated to FITC, TRITC, and HRP were procured from commercial sources (Zymed Lab Inc., San Francisco, CA, USA). Unless otherwise mentioned, all chemicals used for oocyte and embryo manipulations and Western blotting experiments were purchased from Sigma. 


\section{Sperm-head preparation}

Boar spermatozoa were washed by suspending in cold $\left(4{ }^{\circ} \mathrm{C}\right)$ PBS and centrifuged. The pellets were resuspended in cold PBS containing $0.1 \%$ Triton X-100 and sonicated for $1 \mathrm{~min}$ on ice at 30\% intensity with Branson Sonifier (Branson Ultrasonic Corp, Danbury, CT, USA). The suspensions were layered on $70 \%$ sucrose cushions and centrifuged at $100000 \mathrm{~g}$ for $1 \mathrm{~h}$ at $4{ }^{\circ} \mathrm{C}$. They were examined under light microscope to check the purity of the sperm-head preparations, and further sonicated and centrifuged until the purity of the sperm-head fraction was more than $99 \%$.

\section{Oocyte maturation, in vitro fertilization and embryo culture}

Porcine ovaries were collected from a local abattoir. Cumulus-oocyte complexes (COCs) were aspirated from antral follicles (3-6 mm size) and washed three times in HEPES-buffered Tyrode lactate medium containing $0.1 \%$ (w/v) polyvinyl alcohol (TL-HEPES-PVA). For maturation to MIl stage, they were transferred to $500 \mu \mathrm{l}$ drop of maturation medium consisting of tissue culture medium (TCM) 199 (Gibco) supplemented with 0.1\% PVA, $3.05 \mathrm{mM}$ D-glucose, $0.91 \mathrm{mM}$ sodium pyruvate, $0.57 \mathrm{mM}$ cysteine, $0.5 \mu \mathrm{g} / \mathrm{ml}$ luteinizing hormone $(\mathrm{LH})$, $0.5 \mu \mathrm{g} / \mathrm{ml}$ follicle-stimulating hormone (FSH), $10 \mathrm{ng} / \mathrm{ml}$ epidermal growth factor, $10 \%$ porcine follicular fluid, $75 \mu \mathrm{g} / \mathrm{ml}$ penicillin $\mathrm{G}$, and $50 \mu \mathrm{g} / \mathrm{ml}$ streptomycin. The medium drops were overlaid with mineral oil in fourwell dishes (Nunc, Roskilde, Denmark) and incubated at $38.5{ }^{\circ} \mathrm{C}, 5 \% \mathrm{CO}_{2}$ in air. After $22 \mathrm{~h}$ of culture, the oocytes were transferred to fresh maturation medium without $\mathrm{LH}$ and $\mathrm{FSH}$, and cultured for another $22 \mathrm{~h}$.

For in vitro fertilization, the cumulus cells of the matured COCs were removed by vortexing with $0.1 \%$ hyaluronidase in TL-HEPES-PVA medium and washed with Tris-buffered medium (mTBM) (Abeydeera et al. 1998) containing $0.2 \%(\mathrm{w} / \mathrm{v})$ BSA. About 25-30 oocytes were placed in $50 \mu \mathrm{l}$ drops of $\mathrm{mTBM}$, covered with mineral oil, and incubated for about $30 \mathrm{~min}$ until spermatozoa were added. A semen pellet was thawed in PBS containing $0.1 \%$ PVA (PBS-PVA) and centrifuged through two-layered Percoll gradients (60 and 40\%) at 2500 r.p.m. for $10 \mathrm{~min}$. The spermatozoa were resuspended, washed twice in PBS-PVA, and resuspended in mTBM. The sperm suspension was added to the $50 \mu \mathrm{l}$ oocytes-containing medium to give a final sperm concentration of $10^{6} / \mathrm{ml}$. Oocytes were co-incubated with spermatozoa for $6 \mathrm{~h}$, and transferred to $500 \mu \mathrm{l}$ drops of NCSU-23 medium (Petters \& Wells 1993) containing $0.4 \%$ BSA for further culture.

\section{Somatic cell nuclear transfer}

The PEF cells isolation and nuclear transfer were done according to the previously described method (Park et al.
2001). PEF cells were isolated from a day 35 crossbred porcine fetus. The tissue was cut into small pieces and incubated for $30 \mathrm{~min}$ at $37^{\circ} \mathrm{C}$ in PBS containing $0.05 \%$ trypsin and $0.02 \mathrm{mM}$ EDTA. The cell suspension was centrifuged, pellet washed, resuspended, and cultured in Dulbecco's modified Eagle's medium (DMEM) supplemented with $2 \mathrm{mM}$ L-glutamine, $0.1 \mathrm{mM}$ Na-pyruvate, $75 \mu \mathrm{g} / \mathrm{ml}$ penicillin $\mathrm{G}, 50 \mu \mathrm{g} / \mathrm{ml}$ streptomycin, and $15 \%$ (v:v) fetal calf serum (FCS). The cells were cultured for 10-13 days, through two passages before being used as nuclear donors. In vitro matured oocyte freed from cumulus cells were prepared as described above. They were enucleated by aspirating the first-polar body and adjacent cytoplasm in the enucleation medium (TCM 199 supplemented with HEPES, 0.3\% BSA, and $7.5 \mu \mathrm{g} /$ $\mathrm{ml}$ cytochalasin B) with beveled glass pipette, $30 \mu \mathrm{m}$ diameter. The fibroblast cells were injected into the perivitelline space of the oocytes. The oocyte-fibroblast pairs were placed between $0.2 \mathrm{~mm}$ diameter platinum electrodes kept $1 \mathrm{~mm}$ apart in fusion/activation medium. Fusion/activation was induced with two DC pulses $(1 \mathrm{~s}$ interval) of $1.2 \mathrm{kV} / \mathrm{cm}$ for $30 \mu \mathrm{s}$ using BTX Electro-Cell Manipulator 200 (BTX, San Diego, CA, USA). The medium used for injection was the same as for enucleation but without cytochalasin B (CB). The medium used for fusion and activation consisted of $0.3 \mathrm{M}$ mannitol, $1.0 \mathrm{mM}$ $\mathrm{CaCl}_{2}, 0.1 \mathrm{mM} \mathrm{MgCl}_{2}$, and $0.5 \mathrm{mM}$ HEPES. The nuclear transfer embryos were cultured in NCSU-23 medium for various periods to obtain different stage embryos.

\section{RNA isolation}

Frozen-thawed spermatozoa were centrifuged through a discontinuous two-layer Percoll gradient (45/95\%). For each batch of RNA isolation, 20 oocytes, 20 preblastocyst, or 5 blastocyst stage embryos were used. Cumulus cells, zona pellucida, and attached spermatozoa were cleaned from oocytes and embryos according to the methods described earlier. Oocytes and embryos were washed thrice with PBS prepared with diethyl pyrocarbonate-treated (0.1\% DEPC) and -autoclaved distilled water. Samples were transferred to RNase-free Eppendorf tubes, to which $0.6 \mathrm{ml}$ of RLT buffer (Qiagen) and $1 \% \quad \beta$-mercaptoethanol (Sigma) were added. The lysates were processed for RNA isolation or stored at $-80{ }^{\circ} \mathrm{C}$ for future use. Total RNA was isolated with RNeasy Mini or Micro Kit with carrier RNA (Qiagen). Possible contaminating genomic DNA was removed on the column by RNase-free DNase Set (Qiagen). The eluents were supplemented with 20U SUPERase-In RNase inhibitor (Ambion, Austin, TX, USA).

\section{Reverse transcriptase-PCR (RT-PCR) and nested PCR}

CEN2 and CEN3 mRNAs were detected by RT-PCR and nested PCR methods. The RT-PCR was done in two steps. 
In the first step, cDNAs were synthesized using Qiagen Sensiscript RT-PCR kit. Total RNA extracts were preheated at $65^{\circ} \mathrm{C}$ for 5 min to denature secondary structure and chilled rapidly on ice for $10 \mathrm{~min}$. RT buffer, dNTP, RNase inhibitor (SUPERase-In RNase inhibitor, Ambion, Austin, TX, USA) and Oligo-dT primer (Promega), and total RNA were added according to the manufacturer's specification to make the $20 \mu \mathrm{l}$ RT mixture. The RT reactions were run for $180 \mathrm{~min}$ at $37^{\circ} \mathrm{C}$ and the resulting cDNAs were stored at $-20^{\circ} \mathrm{C}$ until used. CEN2 and CEN3 primers were designed according to the published sequence of Homo sapiens centrin genes retrieved from the GenBank (Table 1). PCR was performed in an Eppendorf Mastercycler PCR machine using a HotMaster hot start PCR kit (Eppendorf, Hamburg, Germany). In all experiments, an internal positive control using boar $\beta$-actin primers in the samples and negative controls was performed by substituting the test sample with water. The PCR settings were $94{ }^{\circ} \mathrm{C} 2 \mathrm{~min}, 50$ cycles of $94{ }^{\circ} \mathrm{C} 20 \mathrm{~s}$, $57^{\circ} \mathrm{C} 10 \mathrm{~s}, 68^{\circ} \mathrm{C} 25 \mathrm{~s}$, and $68^{\circ} \mathrm{C} 1 \mathrm{~min}$ for final extension. The PCR products were electrophoresed on $1.2 \%$ agarose gels, stained with $0.5 \mu \mathrm{g} / \mathrm{ml}$ ethidium bromide, and photographed with u.v. illumination. Nested PCR reactions were performed on the firstround PCR products that were analyzed by electrophoresis. The PCR products were sequenced by Applied Biosystems 3730 DNA Analyzer using Applied Biosystems Prism BigDye Terminator cycle sequencing chemistry, at the DNA core facility of the University of Missouri - Columbia. The resultant sequences were edited and analyzed by Genetool Lite (BioTools Inc., Edmonton, Alberta, Canada).

\section{SDS-PAGE and western blotting}

For western blotting, the fibroblast cells were pelleted, washed with PBS, and extracted by boiling for $5 \mathrm{~min}$ with loading buffer (50 mM Tris (pH 6.8), $150 \mathrm{mM} \mathrm{NaCl}$, $2 \%$ SDS, $20 \%$ glycerol, $5 \% \beta$-mercaptoethanol, $0.002 \%$ bromphenol blue) at a concentration of $10^{6}$ cells $/ \mathrm{ml}$. Frozen-thawed spermatozoa were purified by centrifugation through two-layer Percoll gradients, washed with PBS, and extracted with loading buffer at a concentration of $10^{6} / \mathrm{ml}$. Ten microliters of the extracts were loaded per lane. Unfertilized GV and MII oocytes were vortexed with $0.5 \%$ hyaluronidase to remove the cumulus cells completely. For each lane, 150 oocytes or pre-blastocyst stage embryos were dissolved in $10 \mu \mathrm{l}$ loading buffer, boiled for $5 \mathrm{~min}$, and loaded in one lane.

Electrophoresis was done on $4-20 \%$ gradient gels and the resolved proteins were transferred to PVDF membrane using wet transfer system (Towbin et al. 1979). Wash and incubation were done with Tris-buffered saline containing $0.25 \%$ Tween-20 (TBS-TW) and 1\% non-fat milk. The membranes were blocked with $10 \%$ non-fat milk in TBS-TW. They were incubated either with E7 antibody or with $20 \mathrm{H} 5$ overnight at $4{ }^{\circ} \mathrm{C}$. After washing, the membranes were incubated with HRP-conjugated goat anti-mouse IgG (10 000 $\times$ dilution), processed for chemiluminiscence using a commercial kit (SuperSignal, Pierce, Rockford, IL, USA), and visualized by exposing to X-ray film. For simultaneous detection of $\beta$-tubulin and centrin, the PVDF membranes were first incubated with E7 antibody for $1 \mathrm{~h}$ at room temperature, transferred to $\mathrm{mAb}$ $20 \mathrm{H} 5$ without washing, and incubated overnight at $4{ }^{\circ} \mathrm{C}$. They were further processed as described above.

\section{Immunofluorescence labeling}

Diluted spermatozoa were applied to poly-L-lysine-coated coverslips, fixed, and permeabilized with cold $\left(-20^{\circ} \mathrm{C}\right)$ methanol. The PEF cells were grown on coverslips and fixed in a similar way. The cells were sequentially incubated with $5 \%$ normal goat serum (blocking), mAb 20H5, TRITC-conjugated anti-mouse IgG antibody ( $80 \times$ dilution), $\mathrm{Ab}$ E7, FITC-conjugated anti-mouse $\lg \mathrm{G}$ antibody ( $80 \times$ dilution), 4, 6-diamino-2-phenylindole (DAPI) $(5 \mu \mathrm{g} / \mathrm{ml})$, and mounted with VectaShield (Vector Lab Inc., Burlingame, CA, USA). Control labelings were done by following similar protocol, but without incubating with $\mathrm{mAb} 2 \mathrm{OH} 5$.

The oocytes and embryos, except blastocysts, were vortexed with $0.5 \%$ hyaluronidase to remove the cumulus cells. They were briefly (5-7 s) treated with $0.5 \%$ protease and pipetted repeatedly in PBS- $0.5 \%$ BSA to remove the distended zona pellucida. The oocytes were fixed with cold methanol. The blastocysts were fixed without removing the residual zona pellucida. The oocytes and embryos were triple labeled with $\mathrm{mAb}$ $20 \mathrm{H} 5, \mathrm{E} 7$, and DAPI as described above.

Table 1 Centrin primers used for RT-PCR and nested PCR experiments.

\begin{tabular}{|c|c|c|c|c|}
\hline Genes & Expt & Reference & Amplicon size (bp) & Primer sequences \\
\hline \multirow[t]{2}{*}{ CEN2 } & PCR & NM_004344 & 483 & (F) $5^{\prime}$-atccgggaagcttttgatct- $3^{\prime}$ \\
\hline & Nested PCR & & 187 & $\begin{array}{l}\text { (F) } 5^{\prime} \text {-ggagttgggtgagaactiactga-3' } \\
\text { (R) } 5^{\prime} \text {-accatggcaggcactaaatc- } 3^{\prime}\end{array}$ \\
\hline \multirow[t]{2}{*}{ CEN3 } & PCR & NM_004365 & 410 & $\begin{array}{l}\text { (F) 5'-gagccttggggtttggtgta-3' } \\
\text { (R) 5'-ggctccaggcacaaaatag-3' }\end{array}$ \\
\hline & Nested PCR & & 219 & $\begin{array}{l}\text { (F) } 5^{\prime} \text {-gagccttggggtttggtgta-3' } \\
\text { (R) } 5^{\prime} \text {-tagcaacacgtcgcaaattc-3' }\end{array}$ \\
\hline
\end{tabular}

The primers were designed based on published work or human centrin genes retrieved from the GenBank. 


\section{Results}

CEN2 and CEN3 mRNAs are present in oocytes and embryos at all stages of preimplantation development

The presence of CEN2 and CEN3 mRNAs in spermatozoa, oocytes, and embryos were analyzed by RT-PCR and nested PCR. The RT-PCR products of MII oocytes were sequenced to verify if the amplified products are the correct CEN2 and CEN3 cDNAs. The partial sequence of the porcine oocyte CEN2 and CEN3 cDNAs matched with the various mammalian CEN2 and CEN3 genes (Table 2). Porcine centrin genes are phylogenetically closer to human and canine than rodent counterparts. CEN2 and CEN3 cDNA sequences of porcine MII oocyte have been submitted to the GenBank (accession nos. DQ011859 and DQ066552).

The CEN2 mRNA was detected by RT-PCR in GV-stage, MII oocytes, two- and four-cell stage IVF embryos, but not in eight-cell and blastocyst stage embryos (Fig. 1A). However, enhanced amplification by nested PCR revealed the presence of CEN2 mRNA in all stages of pre-implantation embryos (Fig. 1B). CEN2 mRNA was not detectable in the ejaculated boar spermatozoa by RT-PCR or nested PCR. CEN3 mRNA was observed in oocytes and pre-implantation embryos of all stages by RT-PCR method, but not in spermatozoa (Fig.1C). Enhanced amplification by nested PCR revealed CEN3 mRNA in GV and MII oocytes, but not in boar spermatozoa or water control (Fig. 1D).

\section{Centrin is present in porcine spermatozoa, germinal vesicle stage oocytes and cultured embryonic fibroblasts}

The antibody $20 \mathrm{H} 5$ labeled $19 \mathrm{kDa}$ centrin bands in porcine embryonic fibroblast cell and boar sperm extracts (Fig. 2A). The centrin band of the PEF cells migrated slightly faster in the gel than that of the spermatozoa. The PEF and sperm centrins are likely to be cen $2 p$ and cen $1 p$ respectively, because cycling somatic cells express chiefly CEN2, while CEN1 expression is restricted to retina and testicular cells (Middendorp et al. 1997, Hart et al. 1999). The expression of CEN2 gene is shut down in germ cells during the early spermiogenesis stage and compensated by CEN1 expression (Hart et al. 1999). mAb E7 reacted with the $55 \mathrm{kDa} \beta$-tubulin band in both the extracts (Fig. 2B).

To ascertain the isoforms of sperm, oocyte, and fibroblast centrins by precisely aligning the western blotting bands, their extracts were electrophoresed adjacent to the testicular cell extracts in SDS-PAGE. The testicular tissue contains somatic and male germ cells, and hence was expected to possess both cen $1 \mathrm{p}$ and cen $2 p$ isoforms. Western blotting with mAb $20 \mathrm{H} 5$ indeed displayed doublet of bands at $M_{r} 19 \mathrm{kDa}$ (Fig. 2C). The upper and lower bands correspond to, cent1p and cen2p respectively (Wiech et al. 1996, Middendorp et al. 1997, Hart et al. 1999). The immunoreactive protein of boar spermatozoa migrated exactly as the upper band of testicular cell extracts (Fig. 2C). The lower band of the testicular cell extracts coincided precisely with the immunoreactive bands of PEF cell extracts. Centrin was detected in the GV-stage oocytes. It migrated similar to PEF cells or the lower band of the testicular cell extracts, and hence likely to be cen $2 p$. Centrin was not detectable in the extracts of purified sperm heads, MII oocytes, one- or two-cell stage embryos by western blotting (Fig. 2C). The PVDF membranes were probed with $20 \mathrm{H} 5$ and $\mathrm{E} 7$ antibodies to simultaneously detect centrin and $\beta$-tubulin in the same blots, the latter serving as an intrinsic positive control. The GV oocytes, MII oocytes, and one- and twocell embryo extracts displayed approximately similar sized $55 \mathrm{kDa}$ bands, but the centrin band was visible only in the GV oocyte extracts.

\section{Boar sperm and fibroblast centrin becomes undetectable after fertilization or SCNT, and embryonic centrin first, appears at blastocyst stage}

The PEF cells possess cen2p. Anti-centrin antibody mAb $20 \mathrm{H} 5$ labeled the putative centrioles of PEF cells

Table 2 Comparison of porcine partial centrin cDNA sequences with various mammalian centrin genes of the data bank.

\begin{tabular}{|c|c|c|c|c|}
\hline \multirow[b]{2}{*}{ cDNA } & \multicolumn{4}{|c|}{ Homologues } \\
\hline & Species & Annotation & GenBank access no. & Score \\
\hline \multirow[t]{6}{*}{ centrin 2} & Sus scrofa & rcov25b_b121 & gi|52351874 & 908 \\
\hline & Canis familiaris & centrin & gi|57112864 & 628 \\
\hline & Bos taurus & caltractin & gi|61881616 & 617 \\
\hline & Homo sapiens & centrin 2 & gi|13529121 & 605 \\
\hline & Rattus norvegicus & centrin 2 & gi|62667524 & 553 \\
\hline & Mus musculus & centrin 2 & gi|32129280 & 521 \\
\hline \multirow[t]{5}{*}{ centrin 3} & Sus scrofa & reru23c_c16.y1 & gi|52351972 & 757 \\
\hline & Homo sapiens & EF-hand protein 3 & gi|13529247 & 638 \\
\hline & Canis familiaris & centrin 3 & gi|57084872 & 509 \\
\hline & Mus musculus & centrin 3 & gi|31560719 & 353 \\
\hline & Rattus norvegicus & centrin 3 & gi|62642693 & 337 \\
\hline
\end{tabular}




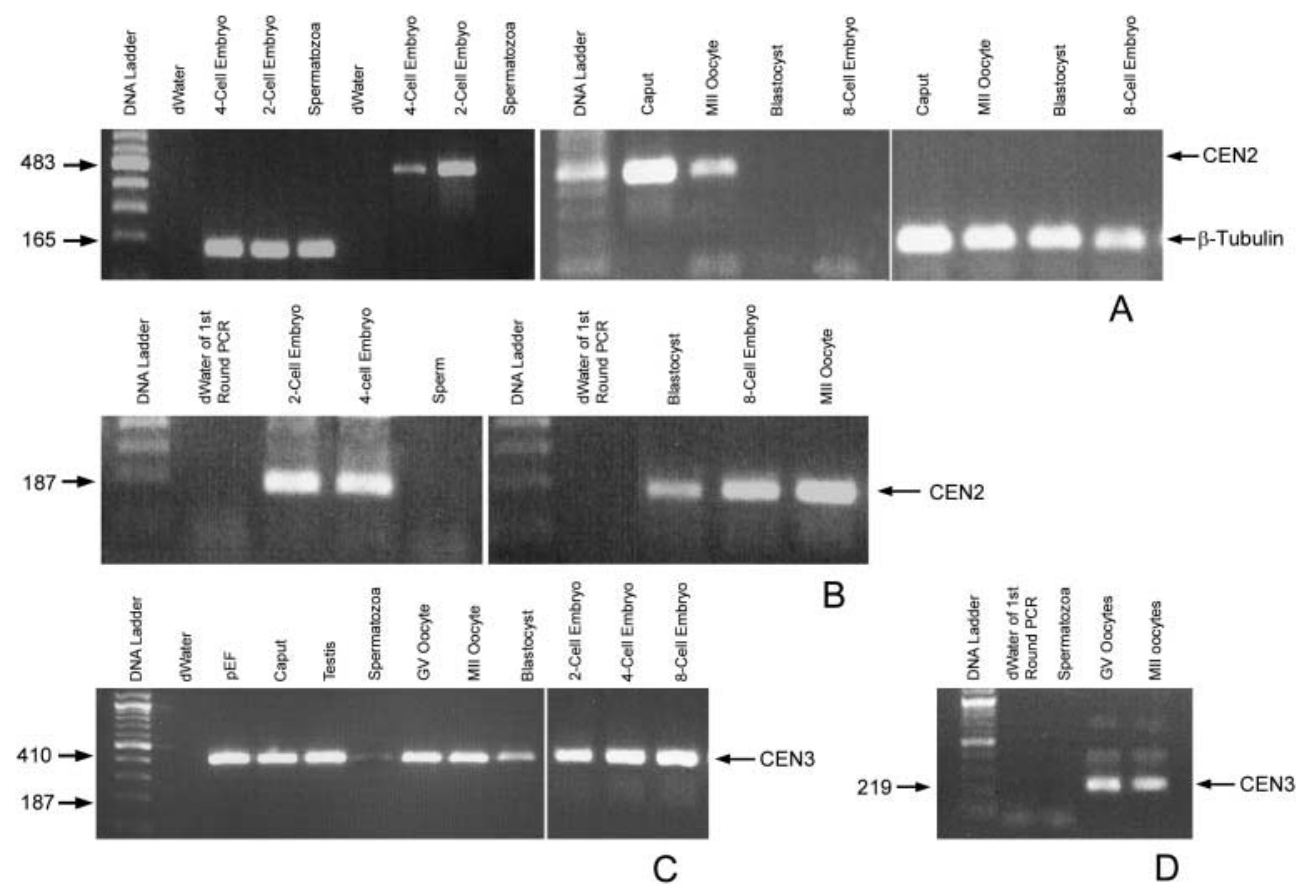

Figure 1 Detection of CEN2 and CEN3 mRNAs by RT-PCR and nested PCR in porcine gametes and embryos. (A) RT-PCR displaying the presence of CEN2 mRNA in the caput epididymal tissues, GV-, MII oocytes, two-, and four-cell stage embryos. Spermatozoa, blastocyst, and eight-cell embryos lacked detectable transcript. $\beta$-Tubulin mRNA was amplified in all lanes except that of spermatozoa. $d$-Water served as a negative control. (B) Nested PCR revealing CEN2 mRNA in blastocysts and eight-cell stage embryos in addition to MIl oocytes, two-, and four-cell stage embryos, but not in the spermatozoa. (C) RT-PCR revealing the presence of CEN3 mRNA in all lanes except that of spermatozoa. (D) Nested PCR showing the presence of CEN3 mRNA in GV and MII oocytes but not in spermatozoa.

(Fig. 3A). In some cells, the centrioles labeled by the anticentrin antibody were visible as two orthogonally oriented cylindrical structures (Fig. 3A; inset) similar to the centriolar duplex. Immunofluorescence of boar spermatozoa labeled with mAb $20 \mathrm{H} 5$ revealed two spots in the connecting piece region of the sperm flagellum corresponding to two residual centrioles (Fig. 3B and C). In the separated sperm head-tails, two centrin spots were observed associated with the proximal part of the tail.

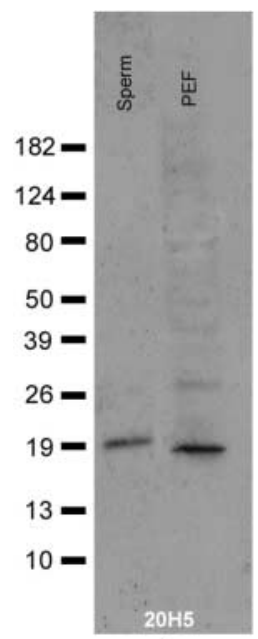

A

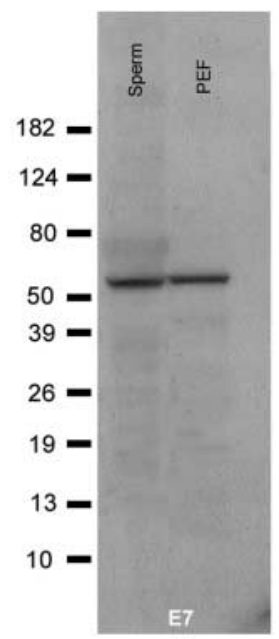

B

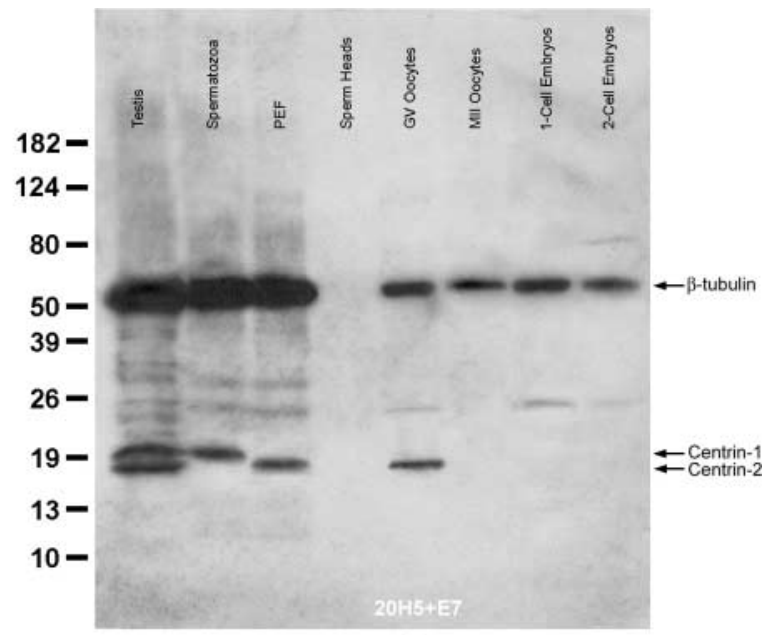

C

Figure 2 Western blots of porcine embryonic fibroblasts (PEF), testis, gamete, and embryo extracts. (A) Western blot labeled with $20 \mathrm{H} 5$ antibody displaying cen $1 p$ in sperm and cen2p in PEF extracts (see text for detail). (B) Western blot labeled with E7 antibody showing $\beta$-tubulin in spermatozoa and PEF extracts. (C) Western blot doubly labeled with E7 and $20 \mathrm{H} 5$ antibodies displaying the presence of centrin in testicular cells, spermatozoa, PEF, GV oocytes but absence in purified sperm heads, MIl oocytes, one-, and two-cell embryos. Testicular cells possessed cen1p and cen2p, while the spermatozoa contained cen 1p, PEF and GV oocytes comprised cen2p. All lanes except that of sperm heads displayed $55 \mathrm{kDa} \beta$-tubulin band. 


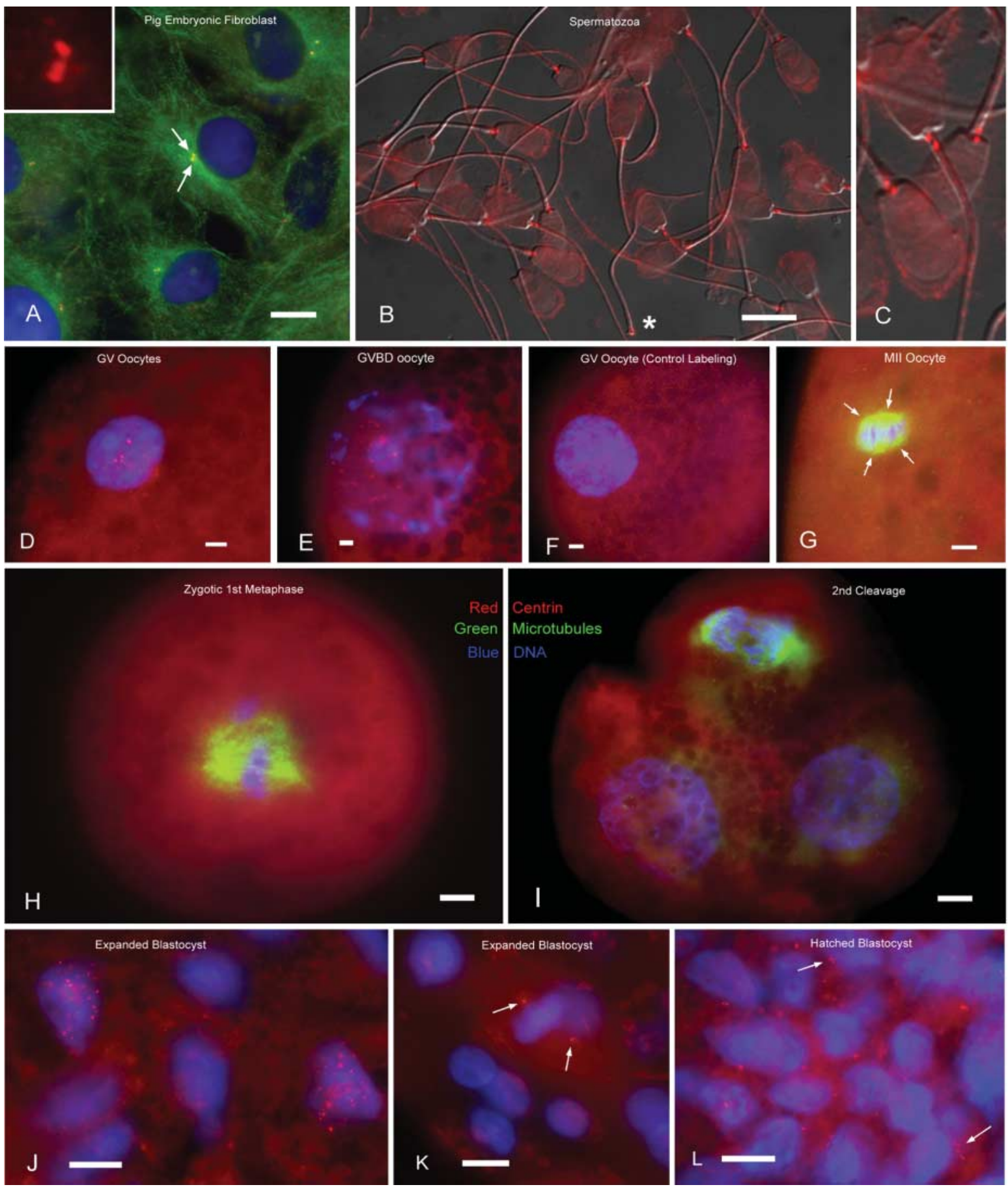

Figure 3 Immunofluorescence of centrin in PEF, spermatozoa, oocytes, and embryos. (A) PEF cells displaying centrin spots, possibly centrioles (arrows in A, magnified in the inset), localized at the juxtanuclear area. (B) Boar ejaculated spermatozoa showing two centrin spots in the sperm tail connecting piece region. In head-tail separated spermatozoa, centrin spots were visible at the proximal end of the tail (asterisk in B). (C) Magnified view of a part of B.

(D) A GV-stage oocyte with interphase-like nucleus displaying centrin particles (red dots) in the perinuclear area. (E) A GVBD-stage oocyte with dispersed centrin particles (red dots) in the nuclear area. (F) Control oocyte labeled with TRITC-conjugated secondary antibody, but omitting the primary antibody. (G) MII oocyte displaying metaphase II spindle (green) but lacking centrin labeling in the spindle polar regions (arrows). (H, I) Embryos during the first $(\mathrm{H})$ and second cleavages (top cell in I) lacking centrin structures in the spindle (green)-pole region. The spindle poles are broadly focused and anastral. (J) Expanded pre-hatched blastocyst with some interphase cells possessing centrin labeling as fine speckles in the perinuclear area while most of other cells lacking recognizable labeling. The number of nuclei in the blastocyst was 230. (K) Expanded pre-hatched blastocyst showing centrin spots in the spindle poles (arrows) of a mitotic cell. In interphase cells, centrin spots were not detectable. (L) Hatched blastocyst displaying defined centrin labeling as one or two spots in the juxtanuclear area. Some cells possess clustered multiple spots (arrows), but not scattered as in pre-hatched blastocysts. The number of nuclei in the blastocyst was 458. A, G, H and I were triple-labeled with antibodies E7 ( $\beta$-tubulin, green), $20 \mathrm{H} 5$ (centrin, red) and DAPI (DNA, blue). The rest were labeled with $20 \mathrm{H} 5$ and DAPI; bar, $5 \mu \mathrm{m}$. 
Freshly isolated GV oocytes displayed centrin-labeled speckles in the nuclear area (Fig. 3D). In germinal vesicle breakdown (GVBD) stage, the centrin appeared as dispersed fine particles in the nuclear area (Fig. 3E). The GV oocytes labeled with goat anti-mouse antibody as control preparations did not show any recognizable structure (Fig. 3F). Centrin was not detectable in the in vitro matured MII oocytes except for a diffuse background (Fig. 2G). The spindle polar regions were unfocussed, broad, and lacked cognate centrosomes or centrin-labeled structures.

Punctate centrin labeling was not observed in the in vitro fertilized zygotes or in the pre-blastocyst embryos by immunofluorescence (Fig. 3H-I). Apparently, the centrin contributed by sperm centrosome was lost after fertilization in the zygotes. Centrin reappeared in the completely expanded blastocysts. The putative centrosomes at the spindle poles of mitotic blastomeres were labeled by mAb 20H5 (Fig. 3K). The interphase cells exhibited various patterns of centrin labeling. In pre-hatched blastocysts, some of the blastomeres showed fine speckles of centrin in the nuclear area (Fig. $3 \mathrm{~J}$ ) as seen in GV oocytes (Fig. 3D). Most of the pre-hatched blastocyst cells lacked a defined labeling except for a diffuse cytoplasmic background. Hatched blastocysts possessing twice as many nuclei as pre-hatched blastocysts revealed putative centrosomes labeled as distinct centrin spots. Most of the cells displayed one or two punctuated spots in the juxtanuclear area (Fig. 3L). Some cells possessed multiple fine particles, but were confined to smaller areas. Blastocysts labeled with TRITCconjugated secondary antibody but omitting mAb $20 \mathrm{H} 5$ did not reveal any recognizable structure (data not shown).

Interestingly, in some hatched blastocysts, the anticentrin antibody labeled eccentrically located curved plate-like structures (Fig. 4A-C). In some blastocysts, the centrin plates occurred in a group of adjacent cells. The nuclei of such cells were relatively more condensed than those of the surrounding cells. However, they are not likely to be the cytokinetic structures since they were not observed in the cells possessing residual mid-zone spindles (data not shown). When co-labeled with anti$\beta$-tubulin antibody, microtubules seemed to emanate centripetally from the centrin plates (Fig. 4D). Possibly, the centrin plates are the junctional complexes that develop between some blastomeres and associate with actin and microtubule bundles (Talbot \& Garrett 2001). Further investigation on the centrin plates will be part of a future research project.

In embryonic fibroblast cells, centrin labeling represents centrioles (see Fig. 3A). To investigate the fate of somatic centrin in zygotes, fibroblast cells were fused with enucleated oocytes. The punctate centrin spots of the PEF cells were detectable during the early pronuclear stage (Fig. 4E). With further in vitro incubation of the embryos, the centrin spots seem to breakdown into smaller particles and disperse around the nuclear area
(Fig. 4F). In the late pronuclear stage nuclear transfer embryos, the punctate centrin spots were not detectable (Fig. 4G). The early cleavage stage nuclear transfer embryos lacked detectable centrin, similar to in vitro fertilized embryos (data not shown).

\section{Discussion}

Mature oocytes and early pre-implantation embryos possess CEN2 and CEN3 mRNAs. But the lack of detectable centrins by western blotting and immunofluorescence with mAb $20 \mathrm{H} 5$ suggests that the CEN2 mRNA of those cells is not translated. Moreover, CEN2 mRNA becomes undetectable by RT-PCR in eight-cell and early blastocyst stage embryos suggesting that it is unlikely to be transcribed de novo by embryonic genome during these stages. The early embryonic cen $2 p$ might have originated before or during oocyte maturation, stored in inactive form, and diluted due to partial degradation during the progress of embryonic cell cycle. Oocytes accumulate stockpiles of various mRNAs, stabilize and block their translation by various mechanisms, such as restricted polyadenylation, binding of masking proteins to $3^{\prime}$ UTR (UTR), or restricted localization (Marello et al. 1992, Seydoux 1996). Early stages of embryonic development largely depend upon programmed expression of such stored maternal mRNAs (Oh et al. 2000, de Moor \& Richter 2001). CEN3 mRNA seems to be more abundant in pre-implantation embryos since it was detected in two-, four-, eight-cell embryos, and blastocysts by RT-PCR. Consistent with the present study, two centrin clones have been isolated from porcine oocytes and embryos (GenBank accession nos. CN032223 and CO951041), both showing a decrease in message abundance between the four-cell and blastocyst stages $(P=0.061$ and 0.056 ; http://genome. rnet.missouri.edu/Swine/), as revealed by microarray studies (Whitworth et al. 2005).

The present study has shown that centrin disperses as fine particles during GVBD and finally becomes undetectable in MII oocytes. Dispersal of the centrin particles in the perinuclear area of GVBD oocytes is likely to be a consequence of centriole degeneration. Centrioles degenerate in developing oocytes (Szollosi et al. 1972) resulting in dispersal of the centrosomal material (Manandhar et al. 2005). Ultrastructurally, the dispersal of the centrosomal material or centrin particles might be reflected by the fragmentation of $\gamma$-tubulin containing multivesicular aggregates in mouse oocytes (Calarco 2000). The dispersed centrin particles are possibly degenerated by proteolysis in the oocyte cytoplasm, because they were not detectable in MII oocytes or early cleavage-stage embryos by western blotting. The molecular pathway of centrin degeneration in oocytes is largely unknown. The centrosomes harbor various molecular species of proteolytic ubiquitin-proteasome pathway (Wigley 


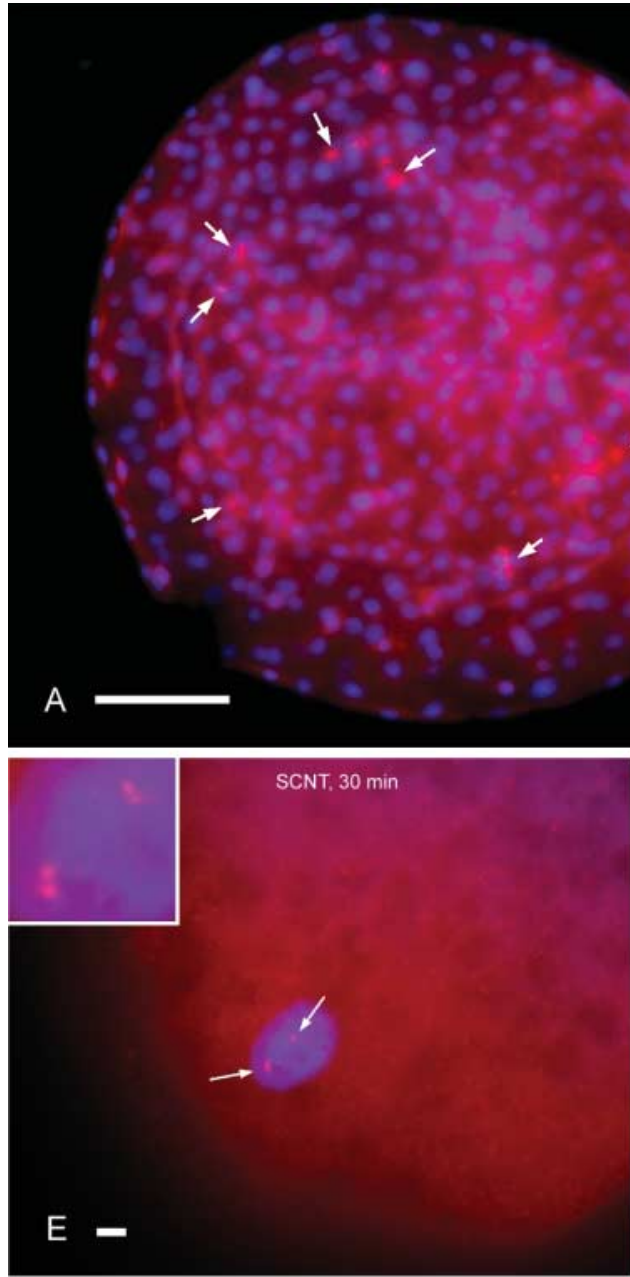

Red - Centrin
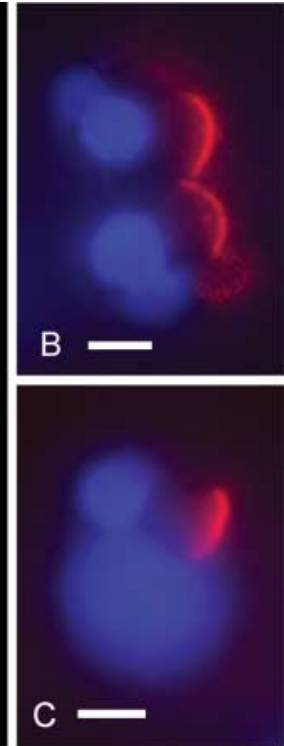

SCNT, 2 h

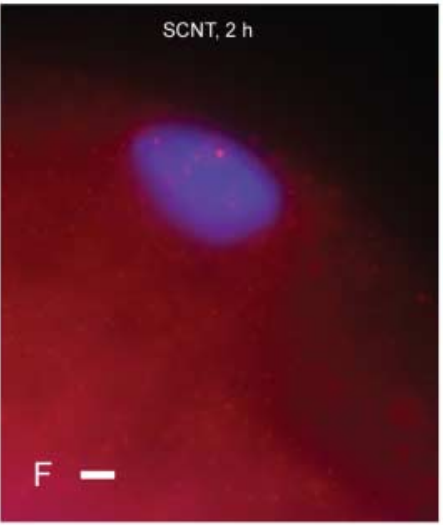

Blue - DNA
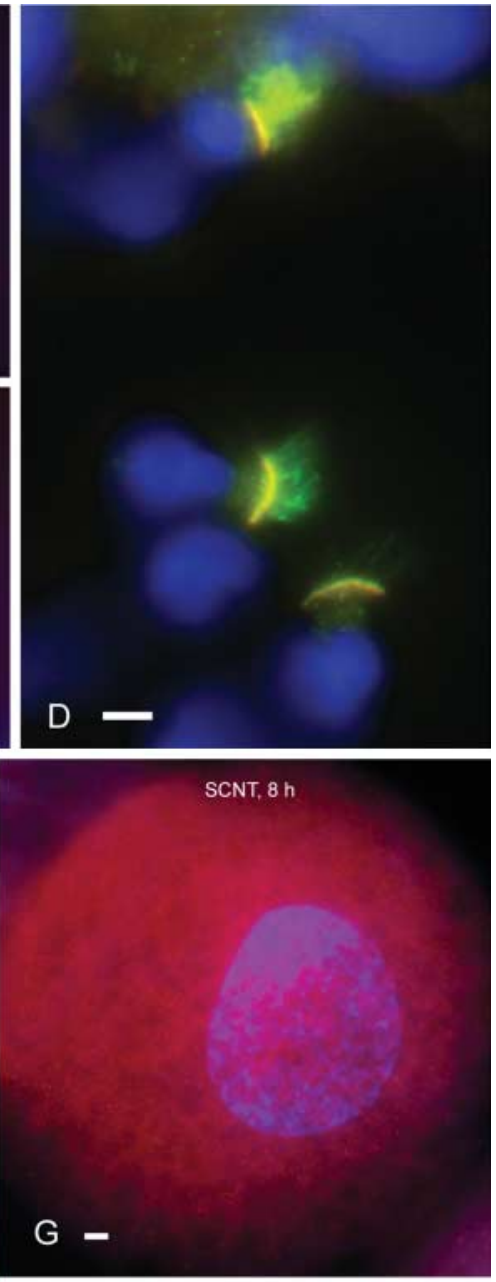

Green - Microtubules

Figure 4 (A)-(D) Centrin-containing plates of porcine blastocysts. (A) A blastocyst displaying plate-like centrin labeling in several cells. (B) and (C) Magnified views of the centrin plates of the individual blastocyst cells. (D) A blastocyst cell double labeled with anti-centrin (red) and anti- $\beta$-tubulin (green) antibodies displaying microtubules emanating centripetally from the centrin plates. The orange color is due to the overlapping of the centrin and microtubule signals. The cells shown in the magnified view did not possess centrin-labeled centrosome. (E)-(G) Centrin in somatic cell nuclear transfer (SCNT; enucleated oocyte fused with embryonic fibroblast) embryos. (E) Early pronuclear stage SCNT embryo showing putative donor cell centrosomes (arrows, magnified in the inset) labeled with anti-centrin antibody. The donor cell was probably in the G2 phase of the cell cycle at the time of fusion, possessing four centrioles revealed as four centrin spots. (F) SCNT embryo at mid-stage of nuclear decondensation, displaying fragmented and dispersed centrin particles. (G) SCNT embryo at the advanced stage of nuclear decondensation, lacking detectable centrin structure except a diffuse labeling. D was triple-labeled with antibodies E7 ( $\beta$-tubulin, green), $20 \mathrm{H} 5$ (centrin, red) and DAPI (DNA, blue). The rest were labeled with $20 \mathrm{H} 5$ and DAPI. Bar in (A) is $100 \mu \mathrm{m}$ and in (B)-(G) are $5 \mu \mathrm{m}$.

et al. 1999), possibly more concentrated in the spermatid centrosomes (Berruti \& Martegani 2005). In the mean time, oocytes and early embryos have highly active proteasomal degradation machinery (Sutovsky et al. 2003). Taken together, it is presumed that the endogenous oocyte centrins and centrin incorporated into oocytes by spermatozoa are mainly degraded through the ubiquitin-proteasome pathway.

Boar spermatozoa have two centrin spots. But the zygotes do not retain centrin contributed by spermatozoa. Loss of sperm-borne centrin has also been noted in human zygotes (Simerly et al. 1999). The oocytes are unable to retain even the somatic cell centrin introduced into them by fusing with embryonic fibroblasts (see also, Manandhar et al. 2004, Zhong et al. 2005). These observations suggest that the zygotic centrosomal apparatus can function without centrin. Interestingly, the lack of centrin in porcine zygotic and early embryonic cells is similar to those of mice (Hiraoka et al. 1989), which do not possess centrioles during these stages of pre-implantation embryonic development (Szollosi et al. 1972).

Among the various isoforms of centrin, the somatic variant cen $2 p$ has been shown to be important for centriolar duplication (Salisbury et al. 2002). Centrin is incorporated into the daughter centriolar cylinders 
during the formation process (D'Assoro et al. 2001). Considering these observations along with ultrastructural localization, it is most likely that centrin is an integral component of centrioles. The present study has shown that porcine zygote and early blastomeres lack detectable amounts of centrin, although the zygotes do possess at least one centriole derived from the sperm-borne, paternal centrosome (Sutovsky et al. 2003). Deficiency of cen $2 p$ could be a limiting factor for centriole replication in the early embryonic cells. Electron microscopic studies by random sectioning have shown the presence of one or two centrioles in the first cleavage spindle poles of human (Sathananthan et al. 1996) and sheep embryos (Crozet 1990, Crozet et al. 2000). Nevertheless, the embryonic cells might inherit some residual cen2p from GV-stage oocytes or synthesize it in a regulated manner from the stored mRNAs. Though undetectable by conventional biochemical approaches, this centrin pool could support some rounds of embryonic centriole replication.

The precise role of cen $1 p$ in germ cells is not known except for a presumption that it may compensate for the lack of cen $2 p$ when the CEN2 gene expression is shut down during spermiogenesis (Hart et al. 1999). It might be important for the generation of the sperm flagellum, similar to the generation of axonemes of the motile cell organelles (Laoukili et al. 2000). Oocytes do not possess cen $1 p$ before fertilization and do not retain the spermderived cen $1 p$ contributed by spermatozoa. These observations indicate that cen $1 \mathrm{p}$ may not have a significant role in fertilization or embryo development. Besides cen $1 p$ and cen $2 p$, somatic cells may contain another well-defined variant, cen3p, and several other uncharacterized isoforms (Wolfrum \& Salisbury 1998). Mouse and human CEN3 genes are homologous to yeast CDC31 gene that regulates spindle pole duplication (Baum et al. 1986, Spang et al. 1993). Human cen3p expression is upregulated during ciliogenesis in nasal epithelial cells and localized in the distal lumen of the basal bodies (Laoukili et al. 2000). Antibody $20 \mathrm{H} 5$ does not recognize cen3p (Middendorp et al. 1997), thus we do not know whether the cen3p protein is present in the spermatozoa or embryonic cells.

Despite the presence of centrioles, the early embryonic spindle poles of non-rodent mammals including that of pig do not seem to contain fully functional centrosomes. The spindles observed during first embryonic mitosis are barrel-shaped; their spindle poles are broad and anastral in rhesus monkeys (Wu et al. 1996), cows (Navara et al. 1994), and pigs (Kim et al. 1996, present study). These spindles are remarkably different from astral spindles of sea urchins (Schatten et al. 1986, 1987), but surprisingly similar to the acentriolar embryonic cleavage spindles of mice (Calarco-Gillam et al. 1983, Schatten et al. 1985). Centrin is absent in both non-murine and murine pre-implantation embryonic spindle poles. Centrin may not be directly involved in microtubule nucleation, but when it was knocked down in HeLa cells, the centrosomes could not form tightly focused spindle poles (Salisbury et al. 2002). The centrosomes of early embryonic cells apparently could not anchor and tether the polar ends of spindle microtubules into tight foci, possibly due to the lack of centrin. During the pronuclear stage, the zygotic centrosome acts as a dominant MTOC and organizes the sperm aster in non-rodent mammals. However, after nuclear envelope breakdown at the onset of first embryonic mitosis, the condensing chromosomes seem to dominate MTOC activity and nucleate microtubules around them (Kim et al. 1996, Wu et al. 1996). From these points of view, there are no fundamental differences between non-murine and murine embryonic spindles regardless of the presence or absence of centrioles in their spindle poles. Nevertheless, the polar regions of unfocused anastral spindles might differ from canonical centrosomes due to the absence of important centrosomal proteins (Debec et al. 1995) other than centriolar proteins. The oocytes and embryonic cells are capable of organizing functional spindles without canonical centrosome via an acentrosomal pathway (Manandhar et al. 2005).

Interestingly, centrin reappearance in the blastocyst cells follows a dynamically opposite sequence of events as that of its disappearance during GVBD oocytes. Centrin accumulation in porcine blastocysts cells was first detected as fine particles around the interphase nuclei, similar to a pattern seen in the GVBD oocytes. Subsequently, the blastomere centrosomes resume somatic cell-like centrin labeling.

In summary, the present study shows that boar spermatozoa possess centrin but lack centrin mRNAs. During fertilization, the sperm-derived centrin is not retained by the ovum, a pattern mimicked by the disappearance of donor fibroblast cell centrin after somatic cell nuclear transfer. In contrast, mature oocytes and early-stage embryos possess centrin mRNAs, which are not translated into proteins. Despite inheritance of centrin and centrioles from the spermatozoa, the early pre-implantation cleavages show broad and anastral spindle poles. While early embryonic centrosomes can function without centrin, its reappearance at the blastocyst stage of porcine embryonic development might be related to the onset of the differentiation of pluripotent embryonic cells.

\section{Acknowledgements}

This work was supported by award no. 2002-02069 from the USDA-National Research Initiative Program in Animal Reproduction and funding from the Food for the 21st Century Program of the University of Missouri-Columbia to PS, and by NIH grant RR 18877 to RSP. J Laurincik was supported by grants from VEGA\#1/1270/04 and DFG. Support from Professor Heiner Niemann (Institute for Animal Science, Mariensee, 
Germany) to $\mathrm{JL}$ is greatly appreciated. We thank Kristin Whitworth for preparing porcine blastocysts, sharing microarray data, sequencing centrin cDNA clones, and helpful discussions. Thanks are due to Nicole Leitman for technical support and Kathryn Craighead for clerical support and manuscript editing. The authors declare that there is no conflict of interest that would prejudice the impartiality of this scientific work.

\section{References}

Abeydeera LR, Wang H, Prather RS \& Day BN 1998 Maturation in vitro of pig oocytes in protein-free culture media: fertilization and subsequent embryo development in vitro. Biology of Reproduction 58 1316-1320.

Baum P, Furlong C \& Byers B 1986 Yeast gene required for spindle pole body duplication: homology of its product with $\mathrm{Ca} 2+-$ binding proteins. PNAS 83 5512-5516.

Berruti G \& Martegani E 2005 The deubiquitinating enzyme mUBPy interacts with the sperm-specific molecular chaperone MSJ-1: the relation with the proteasome, acrosome, and centrosome in mouse male germ cells. Biology of Reproduction 72 14-21.

Boveri T 1900 Zellen-Studien: Ueber die Natur der Centrosomen. G. Fisher, Jena, Germany.

Calarco PG 2000 Centrosome precursors in the acentriolar mouse oocyte. Microscopy Research and Technique 49 428-434.

Calarco-Gillam PD, Siebert MC, Hubble R, Mitchison T \& Kirschner M 1983 Centrosome development in early mouse embryos as defined by an autoantibody against pericentriolar material. Cell 35 621-629.

Callaini G, Riparbelli MG \& Dallai R 1999 Centrosome inheritance in insects: fertilization and parthenogenesis. Biology of the Cell $\mathbf{9 1}$ 355-366.

Chatterjee A, Tanaka T, Parrish JE \& Herman GE 1995 Refined mapping of caltractin in human $\mathrm{Xq} 28$ and in the homologous region of the mouse $\mathrm{X}$ chromosome places the gene within the bare patches (Bpa) and striated (Str) critical regions. Mammalian Genome 6 802-804.

Crozet N 1990 Behavior of the sperm centriole during sheep oocyte fertilization. European Journal of Cell Biology 53 326-332.

Crozet N, Dahirel M \& Chesne P 2000 Centrosome inheritance in sheep zygotes: centrioles are contributed by the sperm. Microscopy Research and Technique 49 445-450.

D'Assoro AB, Stivala F, Barrett S, Ferrigno G \& Salisbury JL 2001 GFPcentrin as a marker for centriole dynamics in the human breast cancer cell line MCF-7. Italian Journal of Anatomy and Embryology 106 103-110.

de Moor CH \& Richter JD 2001 Translational control in vertebrate development. International Review of Cytology 203 567-608.

Debec A, Detraves C, Montmory C, Geraud G \& Wright M 1995 Polar organization of gamma-tubulin in acentriolar mitotic spindles of Drosophila melanogaster cells. Journal of Cell Science $\mathbf{1 0 8}$ 2645-2653.

Errabolu R, Sanders MA \& Salisbury JL 1994 Cloning of a cDNA encoding human centrin, an EF-hand protein of centrosomes and mitotic spindle poles. Journal of Cell Science 107 9-16.

Gueth-Hallonet C, Antony C, Aghion J, Santa-Maria A, Lajoie-Mazenc I, Wright M \& Maro B 1993 Gamma-Tubulin is present in acentriolar MTOCs during early mouse development. Journal of Cell Science 105 157-166.

Hart PE, Glantz JN, Orth JD, Poynter GM \& Salisbury JL 1999 Testisspecific murine centrin, Cetn1: genomic characterization and evidence for retroposition of a gene encoding a centrosome protein. Genomics 60 111-120.
Heald R, Tournebize R, Habermann A, Karsenti E \& Hyman A 1997 Spindle assembly in Xenopus egg extracts: respective roles of centrosomes and microtubule self-organization. Journal of Cell Science 138 615-628.

Hinchcliffe EH, Li C, Thompson EA, Maller JL \& Sluder G 1999 Requirement of Cdk2-cyclin E activity for repeated centrosome reproduction in Xenopus egg extracts. Science 283 851-854.

Hiraoka L, Golden W \& Magnuson T 1989 Spindle-pole organization during early mouse development. Developmental Biology 133 24-36.

Kim NH, Simerly C, Funahashi H, Schatten G \& Day BN 1996 Microtubule organization in porcine oocytes during fertilization and parthenogenesis. Biological Reproduction 54 1397-1404.

Laoukili J, Perret E, Middendorp S, Houcine O, Guennou C, Marano F, Bornens M \& Tournier F 2000 Differential expression and cellular distribution of centrin isoforms during human ciliated cell differentiation in vitro. Journal of Cell Science 113 1355-1364.

LeDizet M, Beck JC \& Finkbeiner WE 1998 Differential regulation of centrin genes during ciliogenesis in human tracheal epithelial cells. American Journal of Physiology 275 1145-1156.

Levy YY, Lai EY, Remillard SP, Heintzelman MB \& Fulton C 1996 Centrin is a conserved protein that forms diverse associations with centrioles and MTOCs in Naegleria and other organisms. Cell Motility and the Cytoskeleton 33 298-323.

Mazia D, Harris PJ \& Bibring T 1960 The multiplicity of mitotic centers and the time course of their duplication and separation. Journal of Biophysical and Biochemical Cytology 71-20.

Manandhar G \& Schatten G 2000 Centrosome reduction during rhesus spermiogenesis: $\gamma$-tubulin, centrin, and centriole degeneration. Molecular Reproduction and Development 56 502-511.

Manandhar G, Simerly C, Salisbury JL \& Schatten G 1999 Centriole and centrin degeneration during mouse spermiogenesis. Cell Motility and the Cytoskeleton 43 137-144.

Manandhar G, Simerly C \& Schatten G 2000 Centrosome reduction during mammalian spermiogenesis. Current Topics in Developmental Biology 49 343-363.

Manandhar G, Schatten H, Lai L, Ezashi T, Letko J, Laurincik J, Caamano J, Sutovsky M, Day B \& Sutovsky P 2004 37th Annual meeting of the society of the study of reproduction. Biology of Reproduction 146a http://abstracts.co.allenpress.com/pweb/ssr2004/ document $/$ ID $=36151$.

Manandhar G, Schatten H \& Sutovsky P 2005 Centrosome reduction during gametogenesis and its significance. Biological Reproduction 72 2-13.

Marello K, LaRovere J \& Sommerville J 1992 Binding of Xenopus oocyte masking proteins to mRNA sequences. Nucleic Acids Research 20 5593-5600.

Middendorp S, Paoletti A, Schiebel E \& Bornens M 1997 Identification of a new mammalian centrin gene, more closely related to Saccharomyces cerevisiae CDC31 gene. PNAS 94 9141-9146.

Navara CS, First NL \& Schatten G 1994 Microtubule organization in the cow during fertilization, polyspermy, parthenogenesis, and nuclear transfer: the role of the sperm aster. Developmental Biology $16229-40$

Novakova M, Draberova E, Schurmann W, Czihak G, Viklicky V \& Draber P 1996 gamma-Tubulin redistribution in taxol-treated mitotic cells probed by monoclonal antibodies. Cell Motility and the Cytoskeleton 33 38-51.

Oh B, Hwang S, McLaughlin J, Solter D \& Knowls BB 2000 Timely translation during the mouse oocyte-to-embryo transition. Development 127 3795-3803.

Palacios MJ, Joshi HC, Simerly C \& Schatten G 1993 Gamma-tubulin reorganization during mouse fertilization and early development. Journal of Cell Science 104 383-389.

Palazzo RE, Vaisberg E, Cole RW \& Rieder CL 1992 Centriole duplication in lysates of Spisula solidissima oocytes. Science $\mathbf{2 5 6}$ 219-221. 
Paoletti A, Moudjou M, Paintrand M, Salisbury JL \& Bornens M 1996 Most of centrin in animal cells is not centrosome-associated and centrosomal centrin is confined to the distal lumen of centrioles. Journal of Cell Science 109 3089-3102.

Park KW, Cheong HT, Lai L, Im GS, Kuhholzer B, Bonk A, Samuel M, Rieke A, Day BN, Murphy CN et al. 2001 Prather RS Production of nuclear transfer-derived swine that express the enhanced green fluorescent protein. Animal Biotechnology 12 173-181.

Petters RM \& Wells KD 1993 Culture of pig embryos. Journal of Reproductive Fertilization 48 61-73.

Riparbelli MG, Tagu D, Bonhomme J \& Callaini G 2005 Aster selforganization at meiosis: a conserved mechanism in insect parthenogenesis? Developmental Biology 278 220-230.

Sathananthan AH, Ratnam SS, Ng SC, Tarin JJ, Gianaroli L \& Trounson A 1996 The sperm centriole: its inheritance, replication and perpetuation in early human embryos. Human Reproduction $\mathbf{1 1}$ 345-356.

Schatten G, Simerl C \& Schatten H 1985 Microtubule configurations during fertilization, mitosis, and early development in the mouse and the requirement for egg microtubule-mediated motility during mammalian fertilization. PNAS 82 4152-4156.

Schatten H, Schatten G, Mazia D, Balczon R \& Simerly C 1986 Behavior of centrosomes during fertilization and cell division in mouse oocytes and in sea urchin eggs. PNAS 83 105-109.

Schatten H, Walter M, Mazia D, Biessmann H, Paweletz N, Coffe G \& Schatten G 1987 Centrosome detection in sea urchin eggs with a monoclonal antibody against Drosophila intermediate filament proteins: characterization of stages of the division cycle of centrosomes. PNAS 84 8488-8492.

Schatten G 1994 The centrosome and its mode of inheritance: the reduction of the centrosome during gametogenesis and its restoration during fertilization. Developmental Biology 165 299-335.

Salisbury JL 1995 Centrin, centrosomes, and mitotic spindle poles. Current Opinion in Cell Biology 7 39-45.

Salisbury JL, Suino KM, Busby R \& Springett M 2002 Centrin-2 is required for centriole duplication in mammalian cells. Current Biology 12 1287-1292.

Schiebel E \& Bornens M 1995 In search of a function for centrins. Trends. Cell Biology 5 197-201.

Seydoux G 1996 Mechanisms of translational control in early development. Current Opinion in Genetics \& Development 6 555-561.

Simerly C, Zoran SS, Payne C, Dominko T, Sutovsky P, Navara CS, Salisbury JL \& Schatten G 1999 Biparental inheritance of gammatubulin during human fertilization: molecular reconstitution of functional zygotic centrosomes in inseminated human oocytes and in cell-free extracts nucleated by human sperm. Molecular Biology of the Cell $102955-2969$.

Spang A, Courtney I, Fackler U, Matzner M \& Schiebel E 1993 The calcium-binding protein cell division cycle 31 of Saccharomyces cerevisiae is a component of the half bridge of the spindle pole body. Journal of Cell Biology 123 405-416.

Sutovsky P, McCauley TC, Sutovsky M \& Day BN 2003 Early degradation of paternal mitochondria in domestic pig (Sus scrofa) is prevented by selective proteasomal inhibitors lactacystin and MG132. Biology of Reproduction 68 1793-1800.
Szollosi D, Calarco P \& Donahue RP 1972 Absence of centrioles in the first and second meiotic spindles of mouse oocytes. Journal of Cell Science 11 521-541.

Talbot NC \& Garrett WM 2001 Ultrastructure of the embryonic stem cells of the 8-day pig blastocyst before and after in vitro manipulation: development of junctional apparatus and the lethal effects of PBS mediated cell-cell dissociation. Anatomical Record 264 101-113.

Tanaka T, Okui K \& Nakamura Y 1994 Assignment of the human caltractin gene (CALT) to Xq28 by fluorescence in situ hybridization. Genomics 24 609-610.

Towbin H, Staehelin T \& Gordon J 1979 Electrophoretic transfer of proteins from polyacrylamide gels to nitrocellulose sheets: procedure and some applications. PNAS 76 4350-4354.

Whitworth KM, Agca C, Kim JG, Patel RV, Springer GK, Bivens NJ, Forrester LJ, Mathialagan N, Green JA \& Prather RS 2005 Transcriptional profiling of pig embryogenesis by using a $15-\mathrm{K}$ member unigene set specific for pig reproductive tissues and embryos. Biology of Reproduction 72 1437-1451.

Wiech H, Geier BM, Paschke T, Spang A, Grein K, Steinkotter J, Melkonian M \& Schiebel E 1996 Characterization of green alga, yeast, and human centrins. Specific subdomain features determine functional diversity. Journal of Biological Chemistry 271 22453-22461.

Wigley WC, Fabunmi RP, Lee MG, Marino CR, Muallem S, DeMartino GN \& Thomas PJ 1999 Dynamic association of proteasomal machinery with the centrosome. Journal of Cell Biology 145 481-490.

Wilson EB 1924 The Cell in Development and Hereditary, 3rd edn New York: The Macmillan Co.

Wilson PG, Fuller MT \& Borisy GG 1997 Monastral bipolar spindles: implications for dynamic centrosome organization. Journal of Cell Science 110 451-464.

Wolfrum U 1991 Centrin- and a-actinin-like immunoreactivity in the ciliary rootlets of insect sensilla. Cell Tissue Research 266 231-238.

Wolfrum U 1992 Cytoskeletal elements in arthropod sensilla and mammalian photoreceptors. Biology of the Cell 76 373-381.

Wolfrum U 1995 Centrin in the photoreceptor cells of mammalian retinae. Cell Motility and the Cytoskeleton 32 55-64.

Wolfrum U \& Salisbury JL 1998 Expression of centrin isoforms in the mammalian retina. Experimental Cell Research 242 10-17.

Wu GJ, Simerly C, Zoran SS, Funte LR \& Schatten G 1996 Microtubule and chromatin dynamics during fertilization and early development in rhesus monkeys, and regulation by intracellular calcium ions. Biology of Reproduction 55 260-270.

Zhong ZS, Zhang G, Meng XQ, Zhang YL, Chen DY, Schatten H \& Sun QY 2005 Function of donor cell centrosome in intraspecies and interspecies nuclear transfer embryos. Experimental Cell Research 306 35-46.

Received 29 September 2005

First decision 24 November 2005

Revised manuscript received 11 April 2006

Accepted 16 June 2006 